\title{
A representação do imaginário infantil nas obras de Monteiro Lobato e Gabriel García Márquez
}

\author{
Elisa. I. C. Dill
}

UNILA

\section{Samir M. Ghaziri}

UNILA

Resumo: Neste trabalho, objetiva-se desenvolver uma análise comparativa entre a obra 'Negrinha' de Monteiro Lobato e 'A luz é como a água' de Gabriel García Márquez. Para tanto, foi analisado de que maneira a criança fantasia, devaneia e imagina, quando seu direito a brincar e se ludibriar são usurpados. Em ambos os contos podemos perceber que a condição de ser criança lhes é tomada. No conto 'Negrinha', a pequena órfã é escravizada, sofre maus tratos, sendo submetida a violências físicas e psicológicas. No conto 'A luz é como a água', as crianças são isoladas do mundo, no apartamento do quinto andar, número 47. Por suas histórias, se considera que as crianças se valem do imaginário para acalentarem suas frustrações e angústias com a vida cotidiana.

Palavras-chave: Imaginário, Devaneio, Monteiro Lobato, Gabriel García Márquez

Abstract: This paper aims to develop a comparative analysis between the work 'Negrinha' by Monteiro Lobato and 'The light is like water' by Gabriel García Márquez. To do so, it was analyzed how the child fantasizes, dreams and imagines, when his right to play and deceive are usurped. In both tales we can see that the condition of being a child is taken. In the story 'Negrinha', the little orphan is enslaved, ill-treated, subjected to physical and psychological violence. In the story 'Light is like water', children are isolated from the world, in the fifth floor apartment, number 47. By their stories, children are considered using imaginary to 
cherish their frustrations and anguish with everyday life.

Keywords: Imaginary, Daydream, Monteiro Lobato, Gabriel García Márquez

\section{Introdução}

O presente estudo busca analisar e comparar dois contos latino-americanos: A luz é como a Água, de Gabriel García Márquez e Negrinha, de Monteiro Lobato. Os dois autores trabalham com um tema universal, notadamente a imaginação infantil e, como será possível perceber, ambos constroem suas histórias e personagens de maneira semelhante.

A escolha por esses autores se deve a latinoamericanidade que ambos transparecem em seus contos. A importância e as contribuições que esses dois escritores legaram para a literatura infantil e juvenil na América Latina é inegável. Nesse contexto, Monteiro Lobato aborda a infância de uma maneira um tanto forte, considerando o momento histórico, em que a criança sofre diferentes formas de violência, algumas bastante graves, como a escravidão. Diante disso, analisamos as possibilidades engendradas para a criança fantasiar, para ser de fato criança, quando sua vida é marcada por maus tratos diários e sua infância usurpada.

Já Gabriel García Márquez, mostra-nos crianças livres de problemas sociais ou que tragam no corpo as marcas da violência física ou psicológica; a o contrário, ele retrata uma infância vivida em harmonia com os pais, os quais lhes atendem em todas as suas necessidades e desejos. Contudo, o que aproxima as crianças de ambos os contos é o fato de que no imaginário e no devaneio, elas se libertam da solidão de suas rotinas e, de certa forma, por meio da fantasia elas se tornam autônomas e sobrevivem a condição imposta por sua realidade.

Neste trabalho, recorremos a três autores para nos auxiliarem na compreensão da teoria do imaginário e do devaneio: Bachelard (1988) que analisa a poética do devaneio; Duran (2001) e Wunenburges (2007) ambos tratam do imaginário e seus desdobramentos. 


\section{Do imaginário ao devaneio}

Imagens são criadas como parte do ato de pensar, são construções obtidas pelas experiências visuais anteriores. Para Durand (2001:41) "todo pensamento humano é uma representação, isto é, passa por articulação simbólica". 0 termo imaginário remete a ideia de vários componentes, como: fantasia, lembranças, devaneios, sonhos, crenças, dentre outros. São várias expressões que se referem ao imaginário humano. Wunenburger (2007:11) afirma que "o imaginário é, portanto, mais próximo das percepções que nos afetam do que das concepções abstratas que inibem a esfera afetiva”.

Consideramos, portanto, que a imagem é formada a partir de um apoio real, o imaginário seria, então, a solução fantasiosa das construções reais. Laplantine/Trindade (1997: 6) recorrem ao pai da psicanálise, Freud, para tratar do assunto:

A psicanálise freudiana, embora também fundamentada na noção de inconsciente, considera os símbolos e o imaginário a partir dos significados contidos na história individual e coletiva. Os indivíduos produzem seus sonhos coletivos (mitos) e sonhos pessoais utilizando imagens que são registros transfigurados e sublimados de suas experiências individuais.

A imagem tem uma contribuição importante na vida da criança, a partir do momento em que ela se reconhece como ser humano, ela começa a criar sua identidade. Sales (2005:116) assinala que a criança forma sua personalidade a partir do momento em ela se reconhece no espelho. Nesse processo de se reconhecer pelo espelho, em que: "a imagem como alvo da identificação não será necessariamente o reflexo da criança no espelho, mas a forma humana em geral, representada paradigmaticamente pela presença do outro". Tratase, aqui, da formação do 'eu' por meio da identificação com a imagem do semelhante, sobretudo a partir da imagem que é lhe devolvida pelo olhar do mesmo.

As crianças se valem do seu rico imaginário para escaparem de suas frustrações e angústias da vida cotidiana. Para Wunenburger (2007:55) “o imaginário lúdico assume assim um papel transicional, assegura uma espécie de válvula de segurança. [...] Pois, da criança ao adulto, brincar atende a mesma necessidade de alívio, de busca de prazer". 
Vale lembrar que outro fruto da imaginação e da fantasia é o devaneio. Segundo Houaiss (2001: 1025) devaneio "é o ato ou efeito de devanear, produto da fantasia, da utopia; sonho; quimera; esperança ou crença vã, estado da pessoa que se deixa levar pela imaginação, pelas lembranças ou pelos sonhos".

Bachelard (1988) afirma que é na solidão que a criança acalma seus sofrimentos e é no devaneio que somos livres:

Essas solidões primeiras, essas solidões de criança, deixam em certas almas marcas indeléveis. [...] Para um devaneio que sabe o preço da solidão. A infância conhece a infelicidade pelos homens. Na solidão a criança pode acalmar seus sofrimentos. Ali ela se sente filha do cosmos, quando o mundo humano lhe deixa a paz. (Bachelard 1988: 94)

E é assim, na solidão, quando devaneia, que a criança conhece a ventura de sonhar. Jorge (2005: 278) pontua que a existência de "uma relação íntima entre o sonho e a fantasia. Se todo sonho é a realização de um desejo, a fantasia é o suporte do desejo".

Nos devaneios da criança, a imagem prevalece acima de tudo. As experiências só vêm depois. Elas vão à contravento de todos os devaneios de alçar voo. A criança enxerga grande, a criança enxerga belo. 0 devaneio voltado para a infância nos restitui à beleza das imagens primeiras (Bachelard 1988: 97)

E assim, é possível observar que no devaneio a criança se realiza como um ser, é o espaço do possível, onde tudo pode acontecer onde tudo é belo, onde não existe a dor.

\section{A representação do imaginário infantil em "Negrinha"}

O conto "Negrinha" foi publicado em 1920, pelo escritor Monteiro Lobato. Hoje, o conto "Negrinha", pode ser encontrado no livro intitulado (Negrinha) da editora Globo. É narrado em terceira pessoa e reflete a indignação perante a crueldade humana, nos tempos da escravidão. O autor apresenta-nos episódios da escravidão infantil e a brutalidade excessiva e marcante contra a pequena Negrinha. A menina tem uma história descrita no corpo; marcas deixadas pela algoz, Dona Inácia, cicatrizes da violência física e psicológica. No decorrer da narrativa, esses castigos variam de puxões de orelha, beliscões no umbigo, 
pontapés, surras com vara de marmelo, e outros mais cruéis, tal como descrito no trecho a seguir:

— Traga um ovo. Veio o ovo. Dona Inácia mesmo pô-lo na água a ferver; e de mãos à cinta, gozando-se na prelibação da tortura, ficou de pé uns minutos, à espera.

- Abra a boca! Negrinha abriu aboca, como o cuco, e fechou os olhos. A patroa, então, com uma colher, tirou da água "pulando" o ovo e zás! na boca da pequena. E antes que o urro de dor saísse, suas mãos amordaçaram-na até que o ovo arrefecesse. Negrinha urrou surdamente, pelo nariz. Esperneou. (Lobato 2008: 2)

Nem tudo no conto é descrito com palavras, muitas ideias ficam subentendidas, por meio de contextos na narração do olhar e do gesto físico, tal como descreve Lobato (2008: 1): "Assim cresceu Negrinha - magra, atrofiada, com os olhos eternamente assustados. Órfã aos quatro anos, por ali ficou feito gato sem dono, levada a pontapés".

A menina, não possui direito ou liberdade de brincar, como as outras crianças, ela vive no silêncio e na escuridão. Negrinha teve sua vida anulada, tornando-se órfã. Vive apenas para os caprichos de Dona Inácia, que a tem consigo apenas para castigá-la sistematicamente.

Os olhos da criança chamam atenção, pois, são descritos como: "assustados". A respeito deles o narrador diz: Negrinha ri para dentro e encontra amparo em seu mundo de silêncio, encontra consolo no cuco do relógio com o qual brinca na sua imaginação.

Cruzava os bracinhos a tremer, sempre com o susto nos olhos. E o tempo corria. E o relógio batia uma, duas, três, quatro, cinco horas - um cuco tão engraçadinho! Era seu divertimento vê-lo abrir a janela e cantar as horas com a bocarra vermelha, arrufando as asas. Sorria-se então por dentro, feliz um instante. (Lobato 2008: 1)

Nascimento (2014: 12) retoma as ideias de Bonnici e relembra que é na imaginação que o ser oprimido encontra refúgio para amenizar suas dores. Lobato (2008: 3) escreve que: "Brincar! Brincar! Como seria bom brincar! — refletiu com suas lágrimas, no canto, a dolorosa martirzinha, que até ali só brincara em imaginação com o cuco". É através do faz- 
de-conta que Negrinha se refugia, pois a imaginação é impenetrável; é lá que a escrava encontra um pouco de paz.

A epifania se dá quando Negrinha observa os brinquedos das meninas; porém o auge se dá quando a criança vê pela primeira vez uma boneca, e com ela pode, por alguns instantes brincar. "Negrinha esqueceu o beliscão, o ovo quente, tudo, e aproximou-se da criatura de louça. Olhou-a com assombrado encanto, sem jeito, sem ânimo de pegá-la”. (Lobato 2008: 3) é neste momento que a criança se reconhece como ser existencial. Como se a boneca fosse um espelho e ali consegue ver seu reflexo.

0 imaginário infantil, nesse momento, mencionado em Lobato, equivale à manifestação do princípio do desejo sobre o princípio da realidade; assim, o jogo simbólico é uma expressão do inconsciente. Quando Negrinha toma consciência de sua humanidade, ela descobre sucessivamente sua relação consigo mesma e com o mundo por intermediário da brincadeira com a boneca, é no momento em que ela atende uma necessidade de alívio através do divertimento que ela entra em êxtase e acaba, estarrecedoramente, morrendo.

Negrinha, coisa humana percebeu nesse dia da boneca, que tinha uma alma. Divina eclosão! Surpresa maravilhosa do mundo que trazia em si e que desabrochava, afinal, como fulgurante flor de luz. Sentiu-se elevada à altura de ente humano. Cessara de ser coisa - e doravante ser-lhe-ia impossível viver a vida de coisa. Se não era coisa! Se sentia! Se vibrava! Assim foi — e essa consciência a matou! (Lobato 2008: 4)

Apesar dos maus tratos sofridos, em alguns momentos a criança consegue encontrar subterfúgio no plano da fantasia. Nascimento (2014:6) menciona os conceitos levantados por Bonnici, com qual, observa que "é na imaginação que o ser oprimido encontra refúgio para amenizar suas dores".

\section{A representação do imaginário infantil em "A luz é como a Água"}

Durante a análise do conto A luz é como a água, escrito por García Márquez em 1978, e que integra o livro Doze Contos Peregrinos, nota-se muito a presença de elementos mágicos na história, tais como a irrealidade tratada como algo real, tendo o narrador como 
testemunha. 0 conto narra à história de dois irmãos, Totó de nove anos e Joel de sete a nos, que convertem a luz elétrica em um meio de navegação. Sua temática aborda aspectos fantásticos.

Os protagonistas deixam sua terra natal com os pais e passam a viver num minúsculo apartamento em Madri, onde a única água navegável é a do chuveiro, segundo a mãe: "Para empezar - dijo la madre-, aquí no hay más aguas navegables que la que sale de la ducha” Márquez (2010: 65) No conto não é revelado o porquê da família migrar para Madri.

Neste conto, não encontramos crianças com problemas econômicos ou que sofrem violência física ou psicológica. Porém, são crianças que sofrem com a falta de lazer; vivem em um condomínio e precisam brincar. Está prática faz parte da natureza. E para que possam brincar é necessária à presença de um adulto para vigia-las.

A convivência em um condomínio requer regras, como: cuidar com o barulho excessivo, silêncio, respeito, práticas de segurança e responsabilidade. Ainda, é necessário respeitar os limites de horários, ou seja, limitar as brincadeiras. E descontentes, as crianças pedem aos pais um barco a remo. Segundo Alves (2013: 66) "Talvez uma possível tentativa de fuga da realidade monótona e entediante que os consumia cotidianamente”. Ao receberem o barco, os meninos descobrem o poder da imaginação e da fantasia.

La noche del miércoles, como todos los miércoles, los padres se fueron al eme. Los niños, dueños y señores de la casa, cerraron puertas y ventanas, y rompieron la bombilla encendida de una lámpara de la sala. Un chorro de luz dorada y fresca como el agua empezó a salir de la bombilla rota, y lo dejaron correr hasta que el nivel llegó a cuatro palmos. Entonces cortaron la corriente, sacaron el bote, y navegaron a placer por entre las islas de la casa. (Márquez 2010: 65)

E assim, a imaginação, dá lugar ao devaneio. Somente nas 'quartas-feiras', quando as crianças ficam sozinhas; elas podem navegar com prazer, e deixar que a imaginação as leve para um estágio psicológico onde podem ser livres. Quebrando as barreiras do possível e o impossível.

Assim, continuaram a navegar por algum tempo, até que seu desejo de explorar 
outros lugares fez com que as crianças peçam outros equipamentos aos pais. Entre os equipamentos pedidos nas palavras de Márquez (2010: 65): “Meses después, ansiosos de ir más lejos, pidieron un equipo de pesca submarina. Con todo: máscaras, aletas, tanques y escopetas de aire comprimido." Necessários para enriquecer seu devaneio.

As crianças eram movidas por um sistema de meritocracia, pois, para ganharem os equipamentos pedidos, deveriam cumprir com sucesso as tarefas que os pais os impunham, condição única para terem seus pedidos atendidos: e, assim, cumpriam as tarefas almejando o desejado. Nas palavras de Márquez (2010: 65) ¿Y si nos ganamos la gardenia de oro del primer semestre? - dijo Joel". As crianças fantasiam porque carecem de algo.

Sarmento (2003: 2) retoma as ideias de Freud, relembrando que o "imaginário infantil corresponde à expressão do princípio do desejo sobre o princípio da realidade, sendo o jogo simbólico uma expressão do inconsciente".

Joel e Totó lançam-se ao mundo da aventura e do devaneio, de maneira intensa, acreditando veemente que navegavam e mergulhavam com tubarões por baixo dos móveis e das camas, explorando terras distantes que só a imaginação os poderia levar. A convicção que eles tinham era tão forte e tão criativa, que até mesmo contagiavam os companheiros da escola, que foram convidados pelos meninos para um festa.

Sua fantasia foi capaz de envolver seus colegas de sala, que, ao visitarem aos irmãos, numa quarta-feira, puderam compartilhar da imaginação e do momento mágico; Alves (2013: 68) destaca o trecho do conto de Márquez: "nesse instante algo de especial acontece, todos os utensílios e objetos da casa começam a levitar sob a forte luz que predominava no espaço". A casa toda é tomada por luz, e todos embarcam na imaginação dos meninos.

Al final del corredor, flotando entre dos aguas, Totó estaba sentado en la popa del bote, aferrado a los remos y con la máscara puesta, buscando el faro del puerto hasta donde le alcanzó el aire de los tanques, y Joel flotaba en la proa buscando todavía la altura de la estrella polar con el sextante, y flotaban por toda la casa sus treinta y siete compañeros de clase [...] (Márquez 2010: 66)

Eis que ocorre o momento de maior tensão, o clímax, onde se mistura o real e o irreal, o fantástico e o fabuloso. É essencial observar que segundo Márquez (2010: 66) 
"Salía por los balcones, se derramaba a raudales por la fachada, y se encauzó por la gran avenida en un torrente dorado que iluminó la ciudad", é neste momento que o imaginário torna-se real e envolve até mesmo a cidade, pois, a luz mencionada no conto; pode ser interpretada como fogo, as chamas tomaram conta do prédio e todos puderam ver o incêndio causado pelas crianças.

Llamados de urgencia, los bomberos forzaron la puerta del quinto piso, y encontraron la casa rebosada de luz hasta el techo. El sofá y los sillones forrados en piel de leopardo flotaban en la sala a distintos niveles, entre las botellas del bar y el piano de cola y su mantón de Manila que aleteaba a media agua como una mantarraya de oro. (MÁRQUEZ, 2010: 66)

Neste momento, quando os bombeiros chegam e encontram a casa coberta de 'luz', ou seja, Fogo; o que antes parecia imaginação das crianças torna-se, neste instante, algo que alcança também o olhar adulto, envolvendo a todos, pois, a inocência das crianças acaba tornando-se uma tragédia.

Segundo Márquez (2010: 66) "y flotaban por toda la casa sus treinta y siete compañeros de clase, eternizados en el instante de hacer pipí. [...]Pues habían abierto tantas luces al mismo tiempo que la casa se había rebosado, y todo el cuarto año eleme ntal [...] se había ahogado" com esta passagem é possível perceber que as crianças iniciaram um incêndio e todos acabaram mortos.

\section{Considerações Finais}

Nas leituras realizados do conto "Negrinha", de Monteiro Lobato, e o conto La luz es como el agua, de Gabriel García Márquez, pode-se perceber que em ambos os contos, as personagens centrais são crianças aprisionadas em uma realidade distinta, na qual sua liberdade infantil se restringe ao imaginário, onde buscam construir o espaço natural para realizarem sua existência; e, assim, escaparem das suas frustrações e angústias da vida cotidiana.

Lobato aponta um estilo mais duro e crítico sobre a infância e seus desdobramentos, a personagem Negrinha tem seu imaginário retratado por violências psicológicas e fís icas e 
seus elementos imaginários estão atrelados à imagem do medo e do horror; uma criança que tem sua infância usurpada, mas que constrói, na fantasia, no brincar, um mundo para fugir de sua realidade, e que, ao fim, arrebata a liberta através da morte.

Sabe-se que a infância é uma invenção moderna e que a partir dela surgiram problemáticas sobre como tratar a criança. Gabriel Garcia Marquez retrata uma infância semelhante à descrita por Lobato e, também, com a realidade atual, pois uma característica semelhante ocorre nos grandes centros urbanos onde a violência e as jornadas de trabalho obrigam as famílias a manter seus filhos isolados da opressora realidade.

As crianças Joel e Totó, do conto de Gabriel García Márquez, se assemelham à personagem de Lobato na condição de prisioneiras, embora em contextos diferentes, e que buscavam a liberdade, pois viviam presas num apartamento, enquanto Negrinha vivia sob o jugo da opressora; de certo modo, suas infâncias foram sufocadas, restando-lhes apenas a imaginação, a fuga da realidade pelo brincar. E em ambos os contos, através do devaneio encontram a liberdade pela morte. 


\section{Bibliografia}

Alves, Danúbia Ferreira (2013), “as representações do imaginário infantil nas obras de Lygia Bojunga e Gabriel García Márquez". Anais do CENA. Volume 1, Número 1. Uberlândia: EDUFU,<http://www.ileel.ufu.br/anaisdocena/wp-content/uploads/2014/ 02/cena3_artigo_12.pdf> (último acesso em 01/06/2017).

Bachelard, Gaston (1988), “A poética do devaneio". São Paulo: Martins Fontes, <https://bibliotecadafilo.files.wordpress.com/2013/11/bachelard-gaston-a-poc3a9ticado-evaneio.pdf> último acesso em 30/05/2017)

Durand, Gilbert (2001), "O imaginário: ensaios acerca da ciência e da filosofia da imagem”, $2^{\underline{a}}$ ed. Rio de Janeiro: DIFEL.

Houaiss, Antônio (2001), “Grande dicionário Houass da Língua Portuguesa”. Rio de Janeiro: Objetiva.

Jorge, Marco Antônio Coutinho (2005), “As quatro dimensões do despertar: sonho, fantasia, delírio, ilusão". Ágora: Estudos em Teoria Psicanalítica, v. 8, n. 2, Rio de Janeiro, 275-289, <http://www.scielo.br/pdf/agora/v8n2/a08v8n2> (último acesso em 30/05/2017).

Laplantine, François/ Trindade, Liana (1997), “O que é imaginário”. São Paulo: PDL. Editora brasiliense<http://files.enfermeiros-unemat.webnode.com/200000029-e2234e31c2/ 0\%20 Que\%20\%C3\%A9\%20Imagin\%C3\%A1rio.pdf > (último acesso em 30/05/2017). Lobato, Monteiro (2008) "Negrinha”. 1a ed. São Paulo: Editora Globo. Márquez, Gabriel García (2010) “A luz é como a água”. In:___ Doze contos peregrinos. 11ª ed. Lisboa, Portugal: Dom Quixote, 65-66.

Nascimento, A. C do (2014), “Uma leitura dos contos: Negrinha de Monteiro Lobato e 0 caso da vara de Machado de Assis" 16 p. Trabalho de Conclusão de Curso (Graduação em Letras)- Universidade Estadual da Paraíba, Guarabira, <http://dspace.bc.uepb.edu.br/jspui/bitstream/123456789/4602/1/PDF\%20 - 
\%20Andr\%C3\%A9\%20Costa\%20do\%20Nascimento.pdf> (último acesso em 30/05/ 2017).

Sales, Léa Silveira (2005), "Posição do estágio do espelho na teoria lacaniana do imaginário". Rev. Dep. Psicol, UFF, v. 17, n. 1, Rio de Janeiro, 113-127. <http://s3.amazonaws.com/academia.edu.documents/37163352/Estagio_do_espelho_Fr actal.pdf?disposition=inline\%3B\%20filename\%3DPosicao_do_estagio_do_espelho_na_teor ia.pdf> (último acesso em 30/05/2017).

Sarmento, Manuel Jacinto (2003), “Imaginário e culturas da infância”. Cadernos de Educação, v. 12, n. 21, Pelotas, 51-69 <http://www.titosena.faed.udesc.br/Arquivos/ Artigos_infancia/Cultura\%20na\%20Infancia.pdf> (último acesso em 06/06/2017) Wunenburger, Jean-Jacques (2007), “O imaginário”. edições Loyola: São Paulo.

Elisa. I. C. Dill é mestranda do Programa de Pós-Graduação em Literatura Comparada Universidade Federal da Integração Latino-Americana (UNILA). - Bolsista - UNILA Pesquisadora da FROMELE.

Samir M. Ghaziri é doutorando do Magistério Superior da Universidade Federal da Integração Latino Americana - de Literatura Comparada. (UNILA) 